\title{
Measuring Germination Percentage in Wheat
}

Harish Manmathan, Nora L.V. Lapitan*

Department of Soil and Crop Sciences, Colorado State University, Fort Collins, CO, USA

*For correspondence: Nora.Lapitan@colostate.edu

[Abstract] Knowledge of the viability of seeds is a prerequisite for establishing the seeding rate in crop production and for germination-related trait evaluation in crop plants. This method explains a simple procedure to establish germination percentage in wheat seeds.

\section{Materials and Reagents}

1. Wheat seeds

2. Sterile deionized water

3. Filter paper (Whatman No.1)

4. Permanent marker

5. Lab wipes and gloves

6. $5 \%(w / v)$ Sodium hypochlorite

\section{Equipment}

1. Forceps

2. Laminar flow hood

3. Timer

4. $70 \%$ Alcohol and flame

5. Metal forceps

6. Ruler

7. Petri dishes (11 cm diameter)

\section{Procedure}

1. Obtain a representative sample (i.e. seeds of a particular variety or cultivar) of your wheat seeds. Random selection within this sample is required to avoid any bias. The rest of the procedure is done under Laminar flow hood.

2. Wipe the working area with alcohol and alcohol/flame sterilize the forceps.

3. Spread fresh Whatman paper 1 on the petri dish and moisten until thoroughly damp $(\sim 2$ 
$\mathrm{ml}$ water is added in our case). Avoid standing water above the Whatman paper 1.

4. The seeds are placed in petri dishes, covered with disinfecting (5\% (w/v) sodium hypochlorite) for $15 \mathrm{~min}$, stirred, drained, and washed four times with sterile deionized water.

5. Gently place the seeds spread out in the petri dish with a sterile forceps and record time. Use four replicates of five seeds per dish. It is advisable to have extra sets in case of microbial contamination.

6. Place the petri dishes with seeds in a dark place with stable room temperature $\left(\sim 73^{\circ} \mathrm{F}\right)$.

7. Seeds are considered to be germinated when radicle has emerged approximately $\geq 2 \mathrm{~mm}$ (Figure 1). Germination percentage is recorded every $24 \mathrm{~h}$ for 6 days. Keep an eye for contamination. Do not let the whatman 1 paper dry out (Periodically inspect the moisture level with the help of a timer. In our case every $12 \mathrm{~h}, \sim 1 \mathrm{ml}$ sterile water was added under aseptic conditions to each of the petri dishes).

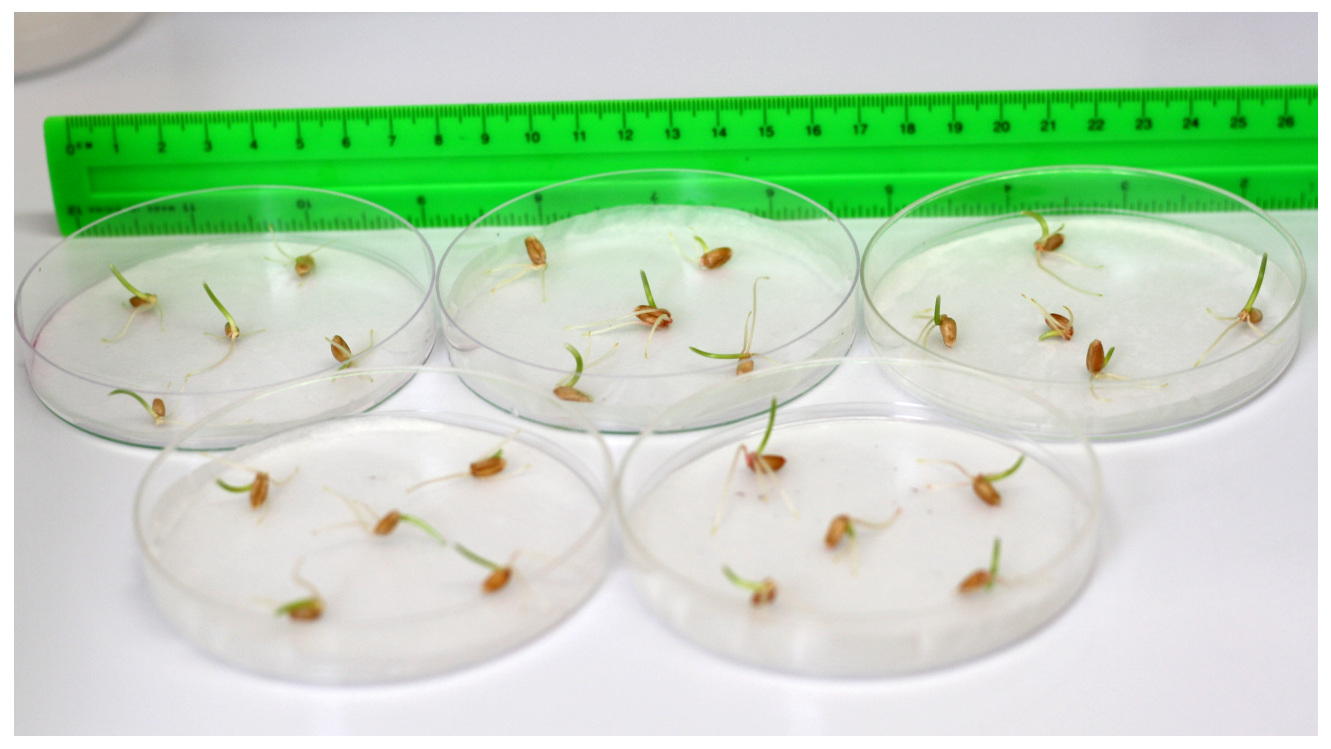

Figure 1. Germinated wheat seeds at the $4^{\text {th }}$ day of germination initiation

8. Germination rate is estimated by using the following formula:

Germination Percentage $=$ seeds germinated/total seeds $\times 100$

\section{Acknowledgments}

This protocol is adapted from Manmathan et al. (2013). 


\section{References}

1. Maynard, Donald N. and George J. Hochmuth. 1997. Knotts Handbook for Vegetable Growers, $4^{\text {th }}$ Edition.

2. Manmathan, H., Shaner, D., Snelling, J., Tisserat, N. and Lapitan, N. (2013). Virusinduced gene silencing of Arabidopsis thaliana gene homologues in wheat identifies genes conferring improved drought tolerance. J Exp Bot 64(5): 1381-1392.

3. New York: John Wiley and Sons, Inc. Yaklich, R.W., Editor. (1985). Rules for Testing Seeds, J Seed Technol. Lansing, Michigan: Association of Official Seed Analysts. Vol. 6, No. 2. 